Assessing the sustainability of community forest management: A case study from Iran

Peer-reviewed author version

Jafari, Ali; Kaji, Hamdollah Sadeghi; AZADI, Hossein; Gebrehiwot, Kindeya;

Aghamir, Fateme \& VAN PASSEL, Steven (2018) Assessing the sustainability of community forest management: A case study from Iran. In: FOREST POLICY AND ECONOMICS, 96, p. 1-8.

DOI: 10.1016/j.forpol.2018.08.001

Handle: http://hdl.handle.net/1942/28642 


\title{
Assessing the sustainability of community forest management: A case study from Iran
}

\begin{abstract}
The development of sustainability criteria and indicators is necessary to assess the current management and to recognize appropriate management approaches towards sustainable forest management (SFM). The aim of this study is to assess the sustainability of current management in the Dopolan community forest and assess alternative management scenarios towards SFM. To this end, we applied multi criteria analysis which consists of three steps: a) developing a primary set of criteria and indicators (C\&Is) on focus groups discussions, b) finalizing and weighing the set of C\&Is, applying a pair wise comparison as well as ranking method, and c) assessing the current forest management regimes and alternative scenarios against a set of C\&Is. As a result, 8 criteria and 40 indicators were selected. Our results indicated that to achieve SFM, the criteria including forest protection against natural and human factors, the establishment of appropriate legal and institutional requirements and socioeconomic functions of forests, are the most important criteria (weighted 14.60\%, $14.28 \%$ and 13.96\%, respectively). Assessing the current management regimes revealed that the criteria consisting of biodiversity conservation and local communities' awareness have the maximum distance to SFM (weighted $7.75 \%$ and $9.18 \%$, respectively). Among the alternative forest management scenarios, the sixth scenario namely conservation and rehabilitation, local investment attraction in forest conservation and rehabilitation, enabling and capacity building of forest inhabitants were realized as the best scenarios (weighted 26.20\%) to achieve SFM. A joint effort of the concerned government
\end{abstract}


forestry officials and local people is needed to enhance the sustainability of all community based forestry models.

Keywords: Sustainable forest management; Criteria and indicators; Central Zagros forests; Dopolan; Iran. 


\section{Introduction}

Since the end of the 1980s, the concept of sustainable development has gained general acceptance. The philosopher Mencius (Legge, 1893) stated "Refraining from overfishing will ensure fishing lasts forever; cutting wood according to the season ensures healthier forests". This is the simplest explanation of harmony and sustainable development. The roots of such ideas can also be found among the influential Chinese philosophies such as Confucianism, Daoism and Buddhism (Xinhong, 2007). In forestry, the concept of sustainable forest management (SFM) has been an accepted principle since the 18th century (Wiersum, 1995). SFM has been recognized as forestry's contribution to sustainable development and participatory forest is an approach to achieve sustainability (Higman et al., 2005). Thus, a simple explanation of SFM is that forest management is based on sustainable development concepts. Accordingly, SFM embraces a wide range of forest management issues including economic, environmental, and social aspects (Mendoza et al., 2003). To date, several hierarchical frameworks have been developed for the SFM concept. Van Bueren and Blom (1997) suggested a standard framework including principles, criteria and indicators (C\&Is). Indeed, the hierarchical frameworks provide a base for sustainable forestry monitoring and assessment of the quality of forest management. The criteria are key elements of sustainability, which introduce general conditions and do not have the ability of measurement, but they usually introduce some indicators, which are measurable. The indicators define different quantitative characteristics and situations in forest including ecological, social and economic, which are useful for detecting changes and monitoring trends in the forest (Van Bueren and Blom, 1997; Mendosa and Prabhu, 2000 a, b; Mendosa et al., 2003; Velázquez et al., 2010; Li et al., 2011; Singh et al., 2011; Abebaw et al., 2012; Zenteno et al., 2013; Martire et al., 2015). 
The FAO in collaboration with partner institutions including the United Nations Environment Programme (UNEP), the Center for International Forestry Research (CIFOR) and the International Union of Forestry Research Organizations (IUFRO) has catalyzed and supported the initiation of C\&Is processes in a number of developing regions that did not earlier participate in the debate. These include African (Nairobi, Kenya, 1995), Pan-European (Lisbon, Portugal, 1998), Montreal (Santiago, Chile, 1995), Amazon (Tarapoto, Peru, 1995), Central America (Tegucigalpa, Honduras, 1997), Asia/South Asia (Bhopal, India, 1999), Near East forest region (Cairo, Egypt, 1996) and Iran (Castaneda, 2000). Each region had to consider a district or forest management unit in which in addition to forest type and topography, social and economic characteristics are considered. Many developing countries participated in the debates, but in later stage, in particular after 2000, SFM C\&I were confused because UN could not come up with a consensus on forests internationally. Since all the C\&Is were made at international level and customizing them was essential for each country, it was difficult to nationalize the C\&Is and customize them in local condition. Maryudi et al. (2012) reviewed the practical considerations in evaluating the outcomes of community forestry. According to them, the core concept of community forestry lays on its attempt to build the active participation of the locals, with the external involvement having a supportive rather than managerial nature. The concept is founded on the recognition of interdependency and intimate synergies between rural people and forests. The C\&I or forest indicator certifications are adapted for a different user group and specific purpose. Participants emphasized the key role of forest certification to use C\&I at local level in forest management practice and the wealth of knowledge and experiences of forest certification schemes to engage with forest management decision makers, both large and small holders. 
Participants also emphasized the use of C\&I, a reference framework for developing and applying forest certification standards (FAO, 2015).

Achieving policy goals that are not clearly backed up by formal regulation or availability of finance is a difficult task (Lidskog and Löfmarck, 2016). For instance, Widman (2015) found that Swedish forest owners with large properties and/or with environmental or heritage-oriented goals are more likely to enter into nature conservation agreements (i.e. to preserve, develop or create areas with high values). Using contrasting empirical data from two Swedish municipalities that have different preconditions for forest related activities, Eggers et al. (2017) invited selected experts to assess the consequences of various management options. Their results indicate that current management practices are favorable for economic aspects (wood production), while a number of scenarios would be better suited to fulfill the Swedish co-equal forest policy goal of production and consideration of environmental issues, such as scenarios with longer rotation periods, a larger share of set-asides and a higher share of continuous cover forestry. The result of the study conducted by Lindahl et al. (2017) also suggests that production values generally have a higher weight in management decisions compared to environmental values.

Socially relevant C\&I reflect the range of forest attributes valued by public. In a recent research on indicators for forest management in Victoria (Australia) by Ford et al. (2017), seven broad valued attributes of forests were identified: Natural; Experiential; Productive; Setting; Social/Economic; Learning; and Cultural. According to Arts and Buizer (2009), since fostering flexible forests is a priority for many nations around the world, some features of the shift "from government to governance" can be traced worldwide, including decentralization, an increased importance of commercial actors, and an increased reliance on market-driven certification schemes. 
Multidimensional analysis is a decision-making method, which is suitable for solving complex problems which include qualitative and quantitative aspects. The SFM is considered as complex problems due to a variety of ecological, social and economical circumstances as well as stakeholder's interests and benefits which are involved in it. In order to achieve SFM, the interest and insights of all stakeholders must be taken into account (Mendosa and Prabhu, 2000a, b). Accordingly, multidimensional analysis could provide a framework for taking into account and adjusting different interests and insights of stakeholders.

Several authors have applied the multidimensional approach using analytical hierarchical process (AHP), analytical network process (ANP), rating and scoring methods to assess the sustainability of forest (Wolfslehner and Vacick, 2008; Tajbar et al., 2008; Balana et al., 2010; Islam et al., 2010). In a study conducted in Iran, Goushegir et al., (2009) used AHP and developed a set of 8 criteria and 28 indicators for timber production and forest conservation in the Kheiroud-Kenar forest. Zande-Basiri and Parvin (2012) used the framework of Pressure-State-Response (PSR) to determine key C\&Is of sustainable forestry in Tang-e Soolak forest in Kohgiluye and BoirAhmad province. Khazaee et al. (2012) investigated the role of policy, planning and institutional frameworks in achieving SFM in Pichit villages and the forests around, using rating and scoring methods.

Zagros mountains' forests management (known as one of the five main vegetative regions in Iran) has experienced massive challenges. The challenges include high dependency of local communities on forest resources, lack of economic and social development in parallel with population growth (Fattahi et al., 2000; Soltani et al., 2009), agricultural land conversion, overexploitation and cutting trees for fuel wood, overgrazing, unsuitable land use, exogenous effects like Arabian dust storm and current periodic drought (Jafari et al., 2012). On the other 
hand, the fulfillment of forest management plans has faced deficits including weak financial support, lack of public perceptions, inappropriate spatial organizing and unreliable data on forest characteristics (Ebrahimi-Rostaghi., 2005; Zand-Basiri et al., 2010). Thus, the development of sustainability criteria and indicators seems to be necessary to assess the current management and to recognize appropriate management approaches towards SFM, in which the sustainability of the region should be provided. This study addresses this approach in the Dopolan community forest as a case study for the central Zagros forest, Iran.

\section{Material and Methods}

\subsection{Study area}

The study area, Dopolan community forest, is a part of Zagros vegetation region which covers 5 million ha from Northwest to South of Iran. The study area is located geographically at $31^{\circ} 56^{\prime}$ $24 "$ to $31^{\circ} 45^{\prime} 8^{\prime \prime} \mathrm{N}$ latitude and $50^{\circ} 36^{\prime} 52^{\prime \prime}$ to $50^{\circ} 43^{\prime} 40^{\prime \prime}$ E longitude (figure 1) covering an area of approximately 2570 ha. The average altitude of this area is $1530 \mathrm{~m}$ above sea level. Dopolan has a semi wet climate in which, the average yearly rainfall fluctuates between 500 and $800 \mathrm{~mm}$ and the average yearly air temperature is $14.2{ }^{\circ} \mathrm{C}$. Soil types vary from Clay-Loam to Silty-Loam and soil erosion is very clear in steep slopes. Dominant vegetation type in this area is Quercus brantii and other types such as Quercus brantii- Fraxinus excelcior, Quercus brantii- Pistacia mutica and Quercus brantii-Cratagus spp. are in the next frequency. There are 12 villages with approximately 4193 people in the study area, which are usually farmer (barley, wheat, rice and fruit trees like pomegranate, peach, apricot) and/or animal husbandry (sheep, goat, cow and bee). The overall goal of forest management in this area is forest protection and conservation, however in 300 ha of the forest development area (Quercus brantii) and in 100 ha forest enrichment with 
endemic species such as Cratagus sp., Amygdalus sp. and Pistacia sp. are under way. In addition, in a $12 \mathrm{~km}$ conservational buffer zone, people are encouraged to grow medicinal plants such as wild celery and fruit trees like forest pear and barberry. The main reason for selecting this region was that this region is recently facing many challenges including high dependency of local communities on forest resources, lack of economic and social development in parallel with population growth. Thus, the development of sustainability criteria and indicators seems to be necessary to assess the current management and to recognize appropriate management approaches towards SFM, in which the sustainability of the region should be regarded.

\section{[Insert Figure 1 here]}

\subsection{Developing sustainability criteria and indicators}

For developing a set of criteria and indicators, two steps of opinion survey were accomplished including focus groups discussion and experts and stakeholders team discussion.

\subsubsection{Focus Groups Discussion: developing a primary set of criteria and indicators}

Focus groups discussion has been introduced by Balana et al., (2010) as a way for learning about opinions, views, attitudes, and experiences of a society or group about a special issue or problem. Tang and Davis (1995) suggest 5 to 8 persons for an ideal focus group in size. To find the right respondents for our research questions that cover a range of perspectives, four different groups were employed. In this study, we organized 157 participants in 28 groups: 16 groups of farmers who manage a farm (six persons in each group), eight groups of female housekeepers who look after the house by themselves as a wife (five persons in each group), two groups of educated people who have professional knowledge and experience about forests and the region (six persons in each group) and two animal husbandry groups who breed and care for farm 
animals (five persons in each groups). Educated people are the specialists who have professional knowledge and experience about forests and the region. In a series of participatory discussions, the purposes of the study were explained for each group and then they were asked about their opinions, views, attitudes, and experiences from forest usage and management. The discussions were organized in the framework of Near East C\&Is process (including 7 criteria and 65 indicators) and Iran's national guideline for forests management assessment and monitoring schemes (Bulletin No. 505 of Forests and Rangelands Organization, including 22 criteria and 83 indicators). The second author played a facilitator role throughout the study. After the normalization of results (Hickey et al., 2007) and elimination or adjustment of the conflicts among answers, the primary list of criteria and indicators were prepared for the next step.

\subsubsection{Experts and stakeholders team: finalizing a set of criteria and indicators}

Balana et al., (2010) believe the selection of these team members should be in terms of representation, professional background, knowledge and experience on the administrative, technical, and historical perspectives regarding community forests in the study area. In addition, some authors (Mendoza et al., 1999; Mendoza and Prabhu, 2000a, b; 2003) suggest a group of 8 to 12 persons for developing C\&Is and carrying out the related analysis such as ranking and/or pair wise comparisons. Taking these rules into consideration, in this study we convened a team of 11 persons including five local stakeholders (two persons as villages Islamic council members, two persons as community leaders and a clergy man), two experts of Provincial Natural Resources Agency (water and soil experts), two researchers of Agricultural and Natural Resources Research Center (forest and rangeland researchers), one Associate and one Assistant professor of Shahrekord University (forestry department). All persons were well familiar with 
the study area and using such a team meant to generate reliable data and integrate technical and experimental aspects in a sound decision-making.

A two-day workshop was held in Dopolan village and on the first day, a primary set of criteria and indicators resulted from the earlier step presented in advance. On the first day of workshop, a 9-point scale was used for a pair wise comparison of criteria and indicators from the local point of view by the experts and stakeholders team (1: weakly important; 3: less important; 5: moderately important; 7: more important; 9: extremely important, with 2, 4, 6, and 8 were also used for intermediate level assessments).

On the second day of workshop, the current management regime was assessed against a weighted and finalized set of C\&Is as it will be mentioned in the following. In addition, six alternative forest management scenarios for appropriate and well-determined utilizations were determined in a participatory manner.

\subsection{Determining the importance of criteria and indicators}

The relative weight of a decision element could be calculated based on the ranks assigned to the decision element by the stakeholders (Balana et al., 2010). Following Mendoza and Prabhu $(2000 \mathrm{a}, \mathrm{b})$, it is supposed that there are $\mathrm{j}$ number of criteria $(\mathrm{j}=1, \ldots, \mathrm{J})$ under a certain principle (p). It is assumed that each criterion ' $\mathrm{j}$ ' has ' $\mathrm{m}$ ' indicators $(\mathrm{m}=1, . ., \mathrm{M})$ and is represented as: $\left\{\mathrm{I}_{\mathrm{j} 1}, \mathrm{I}_{\mathrm{j} 2}, ., \mathrm{I}_{\mathrm{jm}}\right\}$, where $\mathrm{I}_{\mathrm{j} 1}, \mathrm{I}_{\mathrm{j} 2}, ., \mathrm{I}_{\mathrm{jm}}$ are the ' $\mathrm{m}$ ' indicators under the criterion ' $\mathrm{j}$ '. It is supposed that the ranking responses are obtained from $\mathrm{k}$ stakeholders. If the $\mathrm{k}$ respondents assign $\mathrm{r}_{\mathrm{j} 1}, \mathrm{r}_{\mathrm{j} 2}, \ldots, \mathrm{rjk}$ ranks as the criterion $\mathrm{j}$ and $\mathrm{r}_{\mathrm{jm} 1}, \mathrm{r}_{\mathrm{jm} 2}, . ., \mathrm{r}_{\mathrm{jmk}}$ ranks as the respective indicators of under criterion $\mathrm{j}$, then the relative weight for the $j$ th criterion and $m$ th indicator under criterion $\mathrm{j}$, respectively can be calculated as follows: 
$w_{j}=\left[\frac{\sum_{k} r_{j k}}{\sum_{j} \sum_{k} r_{j k}} \times 100\right]$

$w_{j m}=\left[\frac{\sum_{k} r}{\sum_{m} \sum_{k}}\right]$

Where $\mathrm{w}_{\mathrm{j}}$ and $\mathrm{w}_{\mathrm{jm}}$ are the relative weight of the $j$ th criterion and the $m$ th indicator under criterion $\mathrm{j}$, respectively.

\subsection{Assessing the existing management regime performance}

In expert/stakeholders workshop, the participants were asked to 'score' the performance of the existing management scheme against each of the C\&Is elements of sustainability. Then, a scoring method used to assess the results. This is a method used for examining and judging the 'current condition' of each indicator relative to a 'perceived target or desired condition' of the indicators under each criterion in order to evaluate the performance of the forest management. In multi-criteria analysis, a 9-point scale can be used to elicit information. A score is given to each indicator by comparing the indicator's current status relative to some desired condition. $1=$ The indicator is in poor/unfavorable condition relative to its desired condition; $3=$ The indicator is in fair but below the average condition; $5=$ The indicator is in average and acceptable condition relative to its desired condition; $7=$ The indicator is in good condition relative to its desired condition; $9=$ The indicator is in excellent/outstanding performance condition relative to its desired condition. 2, 4, 6, and 8 are intermediate judgments which could also be used in scoring. By using weighted scoring technique (Mendoza and Prabhu, 2000a), the overall performance score of the jth criterion $(\mathrm{Sj})$ can be calculated as a weighted average as follows: 
$S_{j}=\sum_{m} w_{j m} \times S_{j m}$

Where $\mathrm{w}_{\mathrm{jm}}$ is the estimated relative weight of indicator $\mathrm{m}$ (see equation (2)), and $\mathrm{s}_{\mathrm{jm}}$ is the average score of indicator $\mathrm{m}$ (both $\mathrm{w}_{\mathrm{jm}}$ and $\mathrm{s}_{\mathrm{jm}}$ are under criterion $\mathrm{j}$ ). The relative weight $\left(\mathrm{w}_{\mathrm{jm}}\right)$ could be estimated.

\subsection{Assessing alternative management scenarios}

The final stage of this study was to choose a particular forest management scenario that best satisfies the objective of sustainable forest management. Six alternative forest management scenarios resulted from the expert/stakeholders workshop according to Table 3. Then, with respect to the weighted set of C\&Is and using pair wise comparison, six proposed scenarios were compared in order to select the preferred forest management scenario.

\section{Results}

\subsection{Developing the sustainability set of criteria and indicators}

The C\&I set used in this study to assess the sustainability of local forest management was developed in two stages. First, Near East process C\&I set (Castaneda, 2000; 7 criteria and 65 indicators) and Iran's national guideline for SFM (Bulletin No. 505; 22 criteria and 83 indicators) was adapted to reflect the contextual factors relevant to the management problems of community forests in the study area. As a result of this stage 12 criteria and 72 indicators were selected. Then, the proposed sets of C\&I were thoroughly revised at the experts/stakeholders workshop. Finally, 8 criteria and 40 indicators were identified as the final C\&I set. The list of C\&I is presented in Tables 1 and 2, respectively. 


\subsection{Performance of the existing forest management regime}

By using equation (1), the relative importance of each criterion was estimated from the rankings assigned directly to the criterion during the experts/stakeholders' workshop. By using equation (3), the average and weighted 'performance scores' of each of the eight criteria were also

calculated for the existing management. The results of relative importance of criteria and performance of existing management regime are presented in table 1.

[Insert Table 1 here]

As Table1 shows, criterion number 4 (forest ecosystem protection against natural and human factors) and 8 (establishing appropriate legal and institutional conditions) have the highest weight for forest sustainability. However, criterion number 3 (forest biodiversity conservation) and 7 (local awareness about SFM principles) have the lowest weight towards forest sustainability. On the other hand, experts and stakeholders give the highest rank to the current management for its forest ecosystem protection against natural and human factors (criterion 4), forest resources conservation and rehabilitation (criterion 2). However, the current management regime pays less attention to forest biodiversity conservation (criterion 3) and local awareness about SFM principles (criterion 8) in the experts and stakeholders' point of view.

\subsection{Relative importance of the indicators}

The relative weights of the indicators under each criterion were calculated using equation (2). These are 'composite' weights in the sense that all participants' votes via both ranking and pair wise comparison methods were considered. Table 2 presents the calculated relative weights of indicators.

[Insert Table 2 here] 
As Table 2 shows, indicators number I1, I12, I15, I19, I24, I30, I35 and I38 belonging to C1-C8 earned the highest relative weights, respectively. In addition, indicators number I2, I8, I16, I21, I26, I32, I34 and I39 have the lowest weight toward forest sustainability management.

On the other hand, experts and stakeholders gave the highest rank to I4, I10, I13, I23, I24, I31, I33 and I38 belonging to $\mathrm{C} 1-\mathrm{C} 8$, respectively. However, the current management regime has paid less attention to I3, I8, I14, I18, I26, I27, and I36, and I40 belonging to C1- C8, respectively.

\subsection{Assessing alternative forest management scenarios}

Management scenarios S1 through S6 were given scores by the experts/stakeholders against each other using pair wise comparison and with respect to the weighted set of C\&Is (Table 3).

[Insert Table 3 here]

Based on Table 3 the sixth scenario (conservation and rehabilitation, attraction investment in forest conservation and rehabilitation, enabling and capacity building of forest inhabitants) received the highest score, followed by forth scenario (conservation, seasonal grazing, forest enrichment and plantation, to draw forest inhabitants participation). In addition, the first scenario (strict conservation, no grazing, any utilization and cultivation) received the lowest score followed by second scenario (conservation and managed grazing, NTFPs forest products utilization).

\section{Discussion}

\subsection{The framework for customizing C\&Is set from regional/national level to local level}

Customizing regional sustainability forest management C\&Is to national, local or forest management unit (FMU) level is necessary in most cases. According to Pokharel et al. (2015), a 
sustainability index, as a user group self-monitoring tool, is essential in community based forestry to provide a clear picture of forest management practices. This helps indicate the direction where the user groups are heading in terms of sustainability. Overall, sustainability index for individual criteria are useful to provide the information and guidance to local forest management entities to identify key issues that need attention in order to enhance the sustainability of their forests. In this up to down customizing process, decreasing the number of C\&Is is usually inevitable. In the current study, from national to FMU level, C\&Is diminished to $36 \%$ (in the case of criteria) and $48 \%$ (in the case of indicators). A study conducted in Malaysia by Islam et al., (2010), also found a similar result with decreasing to $20 \%$ for customizing C\&Is from regional (Asia/South Asia process) to local level. Zandebasiri and Parvin (2012) diminished $80 \%$ of Near East process C\&Is in order to customize them in another case of Zagros forest. Since the FMU is defined as the area in which a set of determined goals and objectives pursue sustainable management (Zandebasiri et al., 2010), the main reason for decreasing the number of C\&Is is specialization to local problems and conditions and also making them easier and faster for assessment and monitoring. However, FMU is a controversial concept and may be defined as watershed, traditional span or administrative boundaries. In Zandebasiri and parvin (2010), as the only study in this subject in Iran, FMU was defined as traditional span, but the authors believe the integration of ecological boundaries (watershed) and traditional span would result in a better analysis of issues and problems and ultimately in better management actions, as have been applied in the current study.

\subsection{The C\&I set for assessing forest management}


In order to reflect the contextual factors relevant to management problems and characteristics of community forests, after two steps of customization and weighting, $65 \%$ of regional and national level C\&Is was diminished. The highest weight of criteria is related to $\mathrm{C} 4$ and $\mathrm{C} 8$ according to Table 1 which implies the importance of forest ecosystem conservation and the weakness of legal and institutional conditions towards sustainable forest management in experts/stakeholders' point of view. This is completely according to the existing situation, where fuel wood utilization and wood traffic, land conversion, intentional fires, livestock grazing and illegal poaching are most prevalent actions in the study area. This outcome also proves the result of Zandebasiri and Parvin's (2012) study that prioritized legal-institutional condition as the key criterion for the Tang-e-Soolak community forest. However, it contradicts the findings of Jalilova et al.'s (2012) study which observed that legal and institutional framework was rated lower than other criteria. However, there is also congruence between experts/stakeholders' opinion and the performance of the existing management regime in criteria level, as the criteria $\mathrm{C} 4$ and $\mathrm{C} 8$ assigned highest weight either in expert/ stakeholder's point of view or the assessment of the current management regime performance (see Table 1). In addition, the existing management has assigned a high weight for forest resources conservation and rehabilitation which implies the necessity of this subject.

The classification of criteria in terms of ecological (C1-C4), economic (C5 and C6), and social (C7 and C8) shows that $47.91 \%, 26.65 \%$ and $25.39 \%$ of the total weights are allocated to these aspects, respectively, which indicates the importance of conservation especially in ecosystem level (C4: 14.60) in comparison to other aspects from experts/stakeholders' point of view. This contradicts the findings of Jalilova et al. (2012) who found that socio-economic function of the forests was preferable and was the second most important criterion. A study conducted in Nepal 
by Pokharel et al. (2015) also revealed that the user groups believe that socio-economic issues are highly important and need to be addressed in order to motivate local people towards forest management, and rank it into the second highest position. However, the logical utilization of forest products is not ignored and it involves raising the local awareness about SFM principles (C7) and establishing appropriate legal and institutional conditions (C8). Assessing the performance of current management regime shows a similar pattern but it assigns a little more weight to ecological conservation criteria (51.55\% against $47.91 \%)$.

Results show that the ecological indicators I1 under C1, followed by I1 2 under $\mathrm{C} 2$, I15 under C3 and I19 under C4, imply that the conservation of soil, regeneration of trees, habitat restoration and preventing land conversion are the most important factors toward sustainable forest management in the experts/stakeholders point of view. However, the existing management regime pays attention to these factors disproportionately. For example in terms of the maximum and minimum related weight of indicators, it seems that there is an exactly similar pattern in indicators under $\mathrm{C} 2$ and $\mathrm{C} 5$, but for indicators under $\mathrm{C} 7$ and $\mathrm{C} 8$ this is true only for maximum weights of indicators and about $\mathrm{C} 1, \mathrm{C} 3, \mathrm{C} 4$ and $\mathrm{C} 6$ there is no similarity in maximum or minimum relative weights of indicators.

Analyzing economical indicators under $\mathrm{C} 5$ and $\mathrm{C} 6$ indicate that in both experts and stakeholders' point of view, the increasing utilization of NTFPs including fodder, medicinal plants, mushrooms, honey, fruits (I24) is acceptable, but experts/stakeholders recommend establishing an appropriate mechanism for sharing benefits by local communities( I27 under C6) to put it in practice, while the existing management wants to decrease invasions to forest by local communities (I31) due to the existence of such a mechanism. Another point in which both experts/stakeholders and the existing management have consensus is the role of ecotourism 
potential of Dopolan community forest to enhance the livelihood of forest relevant communities (I28) and fulfil other indicators under C6 (I29-I32).

By taking into consideration the social indicators under criteria $\mathrm{C} 7$ and $\mathrm{C} 8$, the results show that the indicator number 33 (increasing formal and informal education of children about the importance of forest and natural resources) has the highest weight in experts and stakeholders' point of view. Therefore, the existing management has targeted primary school students as the dissemination of knowledge about sustainable forest and natural resources management. In addition, raising local community awareness about laws and encouraging law obedience (I37) have the second priority for both experts/stakeholders and the existing management. The weight of I35 [encouraging people to increase investment (time, work and money) in their living environment] is also considerable which may be due to the emigration of most people to urban areas during current decades that led to the depletion of villages from working power and money.

Another worthy point to mention about social indicators is the performance of current management regime which is related to I38 (establishing mechanism of periodic monitoring and controlling of forest management plans), and may be due to the current attempts by Jafari et al., (2015) to develop a framework for ecological monitoring in central Zagros forests in this area (Helen forest protected area).

\subsection{Alternative forest management scenarios}

As Table 3 shows, from S1 to S6 (except S4 - S5), and as scenarios move from merely conservation and forbidden utilization to more free or even regulated utilization and also rehabilitation, the weight of scenarios increase. It means that from experts/stakeholders' point of view the best scenario is the one that pays more attention to conservation and rehabilitation of 
forest especially in a participatory manner and simultaneously recognizes (officially) local community's logical rights of utilization of forest resources. Although the existing management regime is not completely in conformity with any of these scenarios, it could be considered as an intermediate scenario because of its performance in both conservation, rehabilitation and utilization criteria and indicators and it is worthy to be kept and continued with some accommodations.

\section{Conclusion}

Dopolan, as a case study, is a representative of Zagros forest on the whole and in many aspects. Extensive deterioration of basic resources including soil and vegetation triggered from White revolution (1963) in which the nationalization of forests and rangelands took place. As a result, the ownership of local communities was canceled and forests and rangelands were declared as national and common wealth. Therefore, local communities felt their future relation to natural resources ambiguous and tried to pick up their share as much as possible. In addition, after the Islamic revolution (1979) and the imposed war (against Iraq from 1981-1989), the public budget of government shifted to country defense and, therefore, the conservation of natural resources was ignored like many other sectors including infrastructure, industry and agriculture. In this period, population also increased and poverty expanded especially in rural areas. During the two past decades, the government has tried to fulfill multiple plans for natural resources management especially forests, but the results are not satisfactory due to the lack of a comprehensive approach. Our study provided important evidence about the results of these plans in a community forest. As discussed in earlier section, the existing management regime is not in the way of sustainability. In order to visit or go near to sustainability especially in a local level, historical 
and environmental interventions, resource use and management plans, and rules and regulation designs should be holistic and the prioritized preferences of stakeholders should be taken into account. This study introduces a framework for developing a relevant set of C\&Is from local communities' point of view. This framework is applicable in other parts of Zagros forest and other countries with comparable socio-economic and environmental conditions.

\section{Acknowledgment}

We would like to thanks all participants including experts, stakeholders, especially local peoples and members of focus groups for their kindly cooperation and hospitability.

\section{References}

Abebaw, D., Kassa, H., Kassie, G.T., Lemenih, M., Campbell, B., Teka, W., 2012. Dry forest based livelihoods in resettlement areas of Northwestern Ethiopia. Forest Policy and Economics. 20,72-77.

Arts, B., Buizer, M., 2009. Forests, discourses, institutions: a discursive-institutional analysis of global forest governance. Forest Policy and Economics, 11 (5), 340-347.

Balana, B.B., Mathijs, E., Muys, B., 2010. Assessing the sustainability of forest management: An application of multi-criteria decision analysis to community forests in northern Ethiopia. Journal of Environmental Management 91, 1294-1304.

Castaneda, F., 2000. Criteria and indicators for sustainable forest management: international processes, status and the way ahead. Unasylva 203, $34-40$. 
Ebrahimi-Rostaghi, M., 2005. The role of policy and decision making in management and conservation of non-Caspian Forests of Iran. Proceeding of Forest Protection in Sustainable Management Seminar. Iranian Society of forestry 137-151 (In Persian).

Eggers, J., Holmgren, S., Nordström E.M., Lämås, T., Lind, T., Öhman, K. 2017. Balancing different forest values: Evaluation of forest management scenarios in a multi-criteria decision analysis framework. Forest Policy and Economics, https://doi.org/10.1016/j.forpol.2017.07.002

FAO/UNEP., 1996. Expert Meeting on Criteria and Indicators for Sustainable Forest Management in the Near East, Cairo, Egypt, 15-17 October 1996.

FAO. 2015. Strengthening Criteria and Indicators (C\&I) for Sustainable Forest Management (SFM) in Policy and Practice. lobal FAO C\&I Expert Workshop, FAO Rome, Italy 15-16 January, $2015 . \quad$ http://www.fao.org/forestry/42459$\underline{\text { 08248fccad99fbd1f1795db78417a066b.pdf }}$

Fattahi, M., Ansari, N., Abbasi, H., Hasani, M., 2000. Management of Zagros forests (Case Study: Forests of Darbadam in Kermanshah province). Published by Research Institute of Forests and Ranglands, 472p (In Persian).

Ford, R.M., Anderson, N.M., Nitschke, C., Bennett, L.T., Williams, K.J.H. 2017. Psychological values and cues as a basis for developing socially relevant criteria and indicators for forest management. Forest Policy and Economic 78, 141-150.

Goushegir, S.Z., Feghhi, J., Mohajer, R.M., Makhdoum, M., 2009. Criteria and indicators of monitoring the sustainable wood production and forest conservation using AHP (Case study: Kheyrud Educational and Research Forest). African Journal of Agricultural Research 4(10), 1041-1048. 
Hickey, G.M., Innes, J.L., Kozak, R.A., 2007. Monitoring and information reporting for sustainable forest management: A regional comparison of forestry stakeholder perceptions. Jounal of Environmental Management 84, 572-582.

Higman, S., Mayers, J., Bass, S., Judd, N., Nussbaum, R., 2005. The sustainable forestry hand Book. Earth Scan Press, London, 332p.

Islam, I., Siwar, C.S., Islamil, M., Hidayah, N., 2010. Criteria and Indicators for sustainable forest management in Malaysia. American journal of Environmental sciences 6(3), 212218.

Jafari, A., Najafifard, A., Mafigholami, D., 2012. Analytical Network Process approach to sustainable forest management of Zagros. Journal of natural ecosystems IRAN 2(2), 1-10 (In Persian).

Jafari, A., Arman, Z., Soltani, A., Lotfi, A., 2015. Developing a pattern for ecological monitoring in central Zagros forests (Case Study; Helen forested protected area). Journal of Environmental Studies 41(1), 179-191. (In Persian).

Jalilova, G., Khadka, C., Vacik, H., 2012. Developing criteria and indicators for evaluating sustainable forest management: a case study in Kyrgyzstan. Forest Policy and Economics $21,32-43$.

Khazaee, H., Falah, A., Yakhkeshi, A., 2009. Implementation of policy, planning and institutional framework for sustainable forest management. Iranian journal of Forest and Poplar Research 16(4), 599-608 (In Persian).

Legge, J. 1893. The Chinese classics: with a translation, critical and exegetical notes, prolegomena, and copious indexes, Nantian shu ju, Taibei Shi. 
Li, X.S., Luo, Y., Yuan, S., Zhang, Y., Settele, J., 2011. Forest management and its impact on present and potential future Chinese insect biodiversity - A butterfly case study from Gansu Province. Journal for Nature Conservation 19 (5), 285-295.

Lidskog, R., Löfmarck, E., 2016. Fostering a flexible forest: challenges and strategies inthe advisory practice of a deregulated forest management system. For. Policy Econ.62, 177183.

Lindahl, K.B., Sténs, A., Sandström, C., Johansson, J., Lidskog, R., Ranius, T., Roberge, J.-M., 2017. The Swedish forestry model: more of everything? Forest Policy and Economics, 77, 44-55.

Martire, S., Castellani, V., Sala, S., 2015. Carrying capacity assessment of forest resources: Enhancing environmental sustainability in energy production at local scale. Resources, Conservation and Recycling 94, 11-20.

Maryudi, A., Devkota, R.R., Schusser, C., Yufanyi, C., Salla, M., Aurenhammer, H., Rotchanaphatharawit, R., Krott, M. 2012. Back to basics: Considerations in evaluating the outcomes of community forestry. Forest Policy and Economics, 14, 1-5.

Mendoza, G.A., Mcoun, P., Prabhu, R., Sukadri, D., Purnomo, H., Hartanto, H., 1999. Guidelines for Applying Multi-criteria Analysis to the Assessment of Criteria and Indictors. In: Criteria and Indicators Toolbox Series. CIFOR, Bogor. C\&I tool No. 9.

Mendoza, G.A., Prabhu, R., Nyerenda, R., Standa-Gunda, W., Mutimukuru, T., 2003. A community-driven multi-criteria approach to developing indicators of sustainable resource management. Journal of Forest Policy 10 (1), 1-21. 
Mendoza, G.A., Prabhu, R., 2000a. Multi-criteria decision making approaches to assessing forest sustainability using criteria and indicators: a case study. Forest Ecology and Management 131 (1e3), 107-126.

Mendoza, G.A., Prabhu, R., 2000b. Development of methodology for selecting criteria and indicators of sustainable forest management: a case study of participatory assessment. Environmental Management 26(6), 659-673.

Mendoza, G.A., Prabhu, R., 2003. Qualitative multi-criteria approaches to assessing indicators of sustainable forest resource management. Forest Ecology and Management 174(1-3), 329343.

Pokharel, R.K., Neupane, P.R., Tiwari, K.R., Köhl, M. 2015. Assessing the sustainability in community based forestry: A case from Nepal. Forest Policy and Economics 58, 75-84.

Singh, V.S., Pandey, D.N., Prakash, N.P., 2011. What determines the success of joint forest management? Science-based lessons on sustainable governance of forests in India. Resources, Conservation and Recycling 56 (1), 126-133.

Soltani, A., Shamekhi, T., Noori Naieni, M.S., Arabmazar, A., 2009. Analyzing sustainability levels of villages and custom unit in forested areas in Kohgiloieh and Boier Ahmad province (Case study: Tangtamoradi Watershed). Journal of Forest and Wood Products (JFWP) 62(1), 59-78. (In Persian).

Tajbar, S.R., Menaria, B. L., Dugaya, D., Kotwal, P.C., 2008. Sustainable forest management in India. Current Science 94, 996-1001.

Tang, K.C., Davis, A., 1995. Critical factors in the determination of focus group size. Family Practice 12, 474-475. 
Van Bueren, E.L., Blom, E., 1997. Hierarchical Framework for the Formulation of Sustainable Forest Management. Wageningen the Netherlands by Tropenbos Foundation, 97P.

Velázquez, J., Tejera, R., Hernando, A., Núñez, M.V., 2010. Environmental diagnosis: Integrating biodiversity conservation in management of Natura 2000 forest spaces. Journal for Nature Conservation 18 (4), 309-317.

Wiersum, K.F., 1995. 200 years of sustainability in forestry: lessons from history. Environmental Management 19(3), 321-329.

Widman, U., 2015. Shared responsibility for forest protection? Forest Policy and Economics, 50, $220-227$.

Wolfslehner, B., Vacick, H., 2008. Evaluating sustainable forest management strategies with the Analytic Network Process in a Pressure-State-Response framework. Journal of Environmental Management 88(1), 1-10.

Xinhong, T. 2007. Harmony Thought in China's Traditional Philosophy and Its Contemporary Value. Journal of Hefei University (Social Sciences), 24(04), 40-3.

Zandebasiri M., Ghazanfari, H., Sepahvand, A., Fatehi P., 2010. Presentation of decision making pattern for forest management unit under uncertainty conditions (Case study: Taf local area-Lorestan). Iranian Journal of Forest 3(2), 109-120. (In Persian).

Zandebasiri, M., Parvin, T., 2012. Investigation on Importance of Near East Process's criteria and indicators on sustainable management of Zagros forests (Case study: Tang-e-Soolak Water Catchment, Kohgiloye and Boyer Ahmad province). Iranian Journal of Forest and Poplar Research 20(48), 204-216 (In Persian). 
Zenteno, M., Zuidema, P.A., de Jong, W., Boot, R.G., 2013. Livelihood strategies and forest dependence: New insights from Bolivian forest communities. Forest Policy and Economics 26, 12-21. 
Table 1. The relative importance of criteria performance of current management regime (On the basis of ranking method)

\begin{tabular}{|c|c|c|c|c|}
\hline \multirow[t]{2}{*}{ Criteria } & \multicolumn{2}{|c|}{ importance of criteria } & \multicolumn{2}{|c|}{$\begin{array}{l}\text { existing management } \\
\text { regime performance }\end{array}$} \\
\hline & $\%$ RW-Cri. & $\begin{array}{l}\text { SD of } \\
\text { Cri. }\end{array}$ & $\%$ RW-EM & SD of EM \\
\hline $\mathrm{C} 1$ : conservation of soil and water resources & 11.42 & 1.03 & 12.62 & 1.30 \\
\hline $\mathrm{C} 2$ : forest resources conservation and rehabilitation & 11.74 & 1.41 & 15.49 & 2.16 \\
\hline C3: forest biodiversity conservation & 10.15 & 1.63 & 7.75 & 0.83 \\
\hline $\begin{array}{l}\text { C4: forest ecosystem protection (against natural and } \\
\text { human factors) }\end{array}$ & 14.60 & 1.16 & 15.69 & 1.25 \\
\hline C5: forest products utilization & 12.69 & 1.04 & 11.64 & 0.95 \\
\hline C6: social and economic functions of forest & 13.96 & 1.03 & 13.19 & 1.33 \\
\hline C7: local awareness about SFM principles & 11.11 & 1.50 & 9.18 & 1.43 \\
\hline $\begin{array}{l}\text { C8: establishment of appropriate legal and institutional } \\
\text { conditions for SFM }\end{array}$ & 14.28 & 0.81 & 14.53 & 1.48 \\
\hline
\end{tabular}

RW-Cri.: relative weight calculated for each criterion (C1 to $\mathrm{C} 8$ ) using pair-wise comparison during experts/stakeholders workshop and equation (1), SD of Cri.: standard deviation of Cri., RW-EM: relative weight of existing management calculated using pair-wise comparison and equation (1), SD of EM: standard deviation of EM. 
Table 2. The relative importance of indicators and performance of current management regime (on the basis of ranking method)

\begin{tabular}{|c|c|c|c|c|}
\hline \multirow[t]{2}{*}{ Criteria/indicators } & \multicolumn{2}{|c|}{$\begin{array}{l}\text { importance of } \\
\text { indicators }\end{array}$} & \multicolumn{2}{|c|}{$\begin{array}{l}\text { existing management } \\
\text { regime performance }\end{array}$} \\
\hline & \%RW-Ind. & $\begin{array}{l}\text { SD of } \\
\text { Ind. }\end{array}$ & $\%$ RW-EM & SD of EM \\
\hline \multicolumn{5}{|l|}{ C1: conservation of soil and water resources } \\
\hline I1: decreasing erosion and other form of soil degradation & 27.73 & 1.14 & 22.66 & 1.74 \\
\hline I2: increasing soil fertility & 13.02 & 0.83 & 13.10 & 1.48 \\
\hline I3: increasing water maintenance capacity in soil & 15.32 & 1.30 & 11.13 & 0.80 \\
\hline I4: conservation of lowland prone to flood disturbance & 20.43 & 1.16 & 35.25 & 1.74 \\
\hline I5: management of springs and surface runoff & 18.97 & 1.32 & 17.22 & 1.75 \\
\hline \multicolumn{5}{|l|}{ C2: forest resources conservation and rehabilitation } \\
\hline I6: developing the area of planted forest & 10.63 & 1.41 & 9.34 & 1.83 \\
\hline I7: developing green ring and buffers & 13.51 & 1.43 & 9.6 & 1.86 \\
\hline I8: developing agro forestry systems & 8.92 & 1.21 & 8.97 & 1.54 \\
\hline I9: developing dry cultivation of fruit trees & 12.60 & 1.51 & 17.98 & 2.14 \\
\hline I10: restoration of degraded forests & 15.95 & 0.98 & 21.19 & 1.58 \\
\hline I11: forest enrichment by endemic species & 14.24 & 1.20 & 13.34 & 1.51 \\
\hline I12: natural regeneration of endemic species & 24.10 & 1.49 & 19.98 & 2.14 \\
\hline \multicolumn{5}{|l|}{ C3: forest biodiversity conservation } \\
\hline $\begin{array}{l}\text { I13: increasing abundance and distribution of plant and animal } \\
\text { species }\end{array}$ & 27.49 & 1.04 & 34.41 & 1.14 \\
\hline I14: decreasing endangered species living in forest ecosystems & 21.12 & 1.47 & 13.72 & 0.70 \\
\hline I15: habitat restoration and rehabilitation & 27.65 & 2.49 & 17.48 & 2.89 \\
\hline I16: increasing the connectivity and integrity of forest patches & 11.32 & 1.14 & 18.36 & 1.18 \\
\hline $\begin{array}{l}\text { I17: increasing structural diversity of forest stands (age and } \\
\text { diameter classes, deadwoods, stratification) }\end{array}$ & 12.68 & 0.89 & 15.86 & 2.33 \\
\hline \multicolumn{5}{|l|}{$\begin{array}{l}\text { C4: forest ecosystem protection (against natural and human } \\
\text { factors) }\end{array}$} \\
\hline I18: decreasing natural damages (fire, pest and diseases) & 16.35 & 1.36 & 12.28 & 1.83 \\
\hline $\begin{array}{l}\text { I19: decreasing forest encroach due to land use change and } \\
\text { rural development }\end{array}$ & 26.09 & 0.75 & 12.73 & 1.14 \\
\hline I20: management of grazing and induced damages & 14.38 & 1.96 & 16.82 & 2.83 \\
\hline I21: decreasing the use of forest for fuel wood & 7.87 & 1.26 & 17.52 & 1.80 \\
\hline I22: establishing conservation belt around villages & 12.33 & 1.41 & 14.26 & 1.52 \\
\hline I23: increasing the area of protected forest & 23.01 & 2.75 & 24.93 & 1.92 \\
\hline \multicolumn{5}{|l|}{ C5: forest production potential utilization } \\
\hline $\begin{array}{l}\text { I24: increasing NTFPs (fodder, medicinal plants, mushrooms, } \\
\text { honey, fruits) utilization }\end{array}$ & 38.17 & 1.14 & 41.15 & 1.14 \\
\hline I25: utilization of ecotourism potentials & 35.15 & 1.30 & 35.36 & 0.83 \\
\hline I26: management the utilization of fuel wood & 27.10 & 0.83 & 23.50 & 1.18 \\
\hline \multicolumn{5}{|l|}{ C6: social and economic performances of forest } \\
\hline $\begin{array}{l}\text { I27: establishing appropriate mechanism for sharing benefits by } \\
\text { local communities }\end{array}$ & 22.8 & 1.86 & 13.83 & 2.64 \\
\hline I28: enhancing livelihood of forest relevant local households & 15.98 & 0.83 & 15.33 & 1.14 \\
\hline I29: increasing the share of forest in job creation & 16.94 & 0.88 & 14.09 & 2.30 \\
\hline I30: involving forest inhabitants in forest management & 19.61 & 1.14 & 15.86 & 1.18 \\
\hline I31: decreasing invasions to forest by local communities & 12.55 & 0.84 & 26.59 & 1.12 \\
\hline $\begin{array}{l}\text { I32: increasing the participation of local communities, media, } \\
\text { NGOs in forest conservation and management }\end{array}$ & 12.39 & 1.85 & 14.10 & 2.13 \\
\hline \multicolumn{5}{|l|}{ C7: local awareness about SFM principles } \\
\hline $\begin{array}{l}\text { I33: increasing formal and informal education of child about } \\
\text { forest and natural resources importance }\end{array}$ & 24.35 & 0.81 & 29.84 & 1.81 \\
\hline I34: acquainting local communities with the necessity of & 17.30 & 0.95 & 15.21 & 1.16 \\
\hline
\end{tabular}


establishing balance between accessible resources and population growth

I35: encouraging people to increase investment (time, work and money) in their living environment

I36: holding session for raising awareness of forest inhabitants

19.87

1.29

17.82

0.81

about SFM

I37: raising awareness of local communities about laws and

17.38

1.95

11.92

2.54

encouraging obedience of law

21.15

1.29

25.18

1.75

C8: establishment of appropriate legal and institutional conditions for SFM

I38: establishing mechanism of periodic monitoring and controlling of forest management plans

I39: establishing appropriate mechanism for conflicts detection

36.88

1.21

44.11

1.22

I40: moving and embedding appropriate and modern

29.9

33.42

0.81

34.36

1.82

technologies

RW-RM: related weight of indicators calculated using pair wise comparison and equation (2), SD of RM: standard deviation of indicators, RW-EM: related weight of existing management calculated using pair wise comparison and equation (2), SD of EM: standard deviation of EM. 
Table 3. Scores of alternative forest management scenarios

\begin{tabular}{lcc}
\hline Management scenarios & RW-Sc. & SD of Sc. \\
\hline S1: Strictly conservation, no grazing, any utilization and cultivation & 5.51 & 0.89 \\
S2: Conservation and managed grazing, NTFPs forest products utilization & 8.96 & 1.54 \\
$\begin{array}{l}\text { S3: Conservation, seasonal grazing, controlled fuel wood and NTFPs forest products } \\
\text { utilization and cultivation }\end{array}$ & 13.10 & 1.48 \\
$\begin{array}{l}\text { S4: Conservation, seasonal grazing, forest enrichment and plantation, to draw forest } \\
\text { inhabitants participation }\end{array}$ & 23.44 & 1.83 \\
$\begin{array}{l}\text { S5: Conservation, gathering scattered and isolated forest inhabitants, managed grazing, } \\
\text { participatory forest enrichment and plantation }\end{array}$ & 22.75 & 1.14 \\
$\begin{array}{l}\text { S6: conservation and rehabilitation, attraction investment in forest conservation and } \\
\text { rehabilitation, enabling and capacity building of forest inhabitants }\end{array}$ & 26.20 & 1.23 \\
\hline
\end{tabular}

RW-Sc.: related weight of scenarios calculated using pair wise comparison and equation (3), SD of Sc.: standard deviation of Sc. 


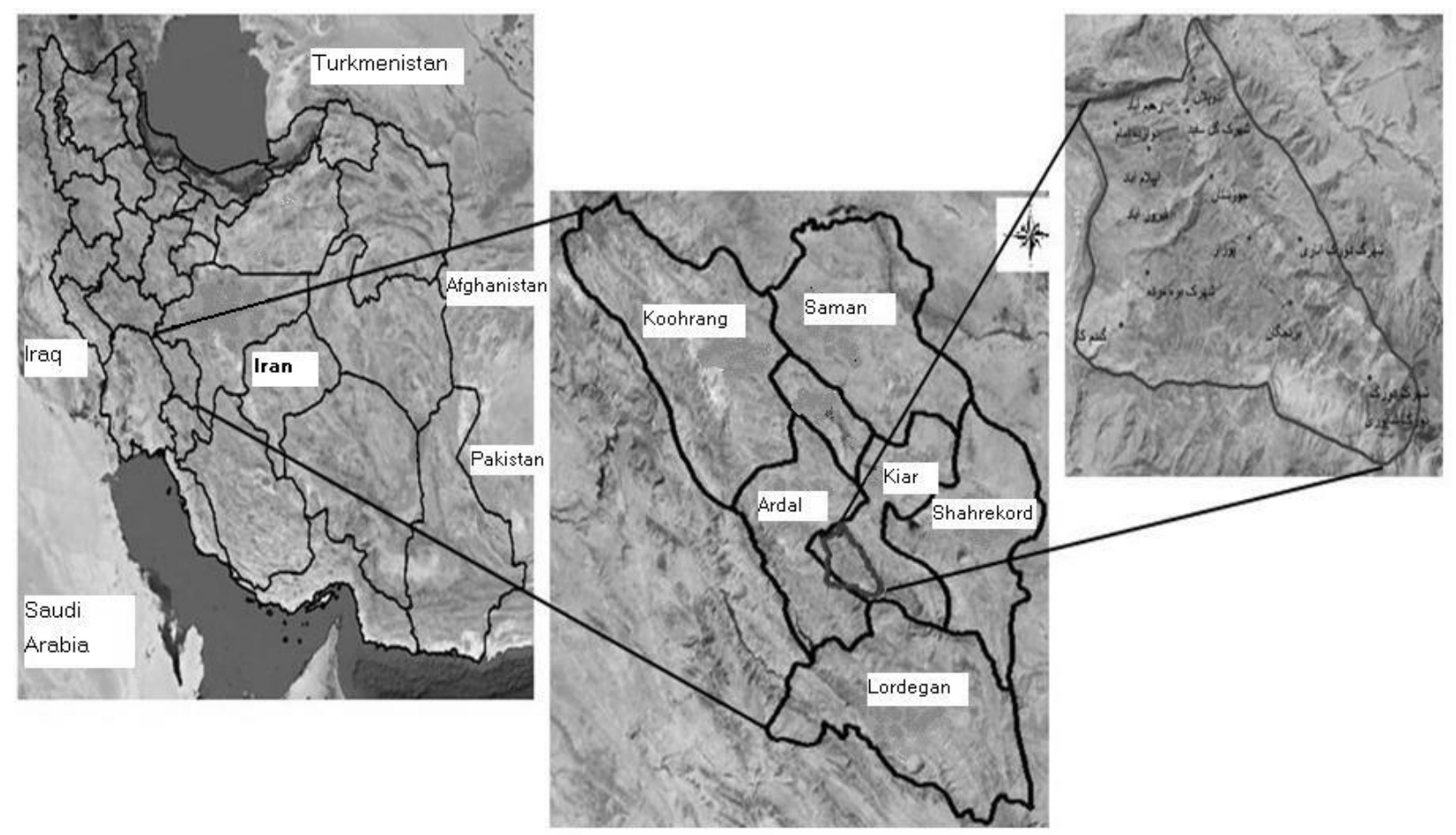

Fig.1. Location of the study area in Iran 